\title{
Assessment of the Energy Impact of Using Building Integrated Photovoltaic and Electrochromic Glazing in Office Building in UAE
}

\author{
Mohammad Katanbafnasab ${ }^{1}$, Bassam Abu-Hijleh ${ }^{2}$ \\ ${ }^{1}$ KEO International Consultants, Abu Dhabi-UAE \\ ${ }^{2}$ Faculty of Engineering \& IT, the British University in Dubai, Dubai-UAE \\ Email: katanbafm@keoic.com, bassam.abuhijleh@buid.ac.ae
}

Received 2013

\begin{abstract}
The aim of this research was to explore the energy benefits and future potential of using Building Integrated Photovoltaic (BIPV) and Electrochromic Glazing (EG) within the climatic conditions of the city of Abu Dhabi. The Integrated Environmental Solutions (IES-VE) energy modeling software was used to assess the energy performance, mainly the reductions in HVAC and lighting, for different configurations and compare that to the base case scenario for south, east, west, and north facing facades. The results showed that the BIPV is most advantageous on the south façade while the EC glazing performs best on the north facing windows. Moreover, the change in sensor location increased the energy savings for both cases, although the change was very marginal compared to the change of the glass properties. Using an automated light control system with dimming for both models, compared against the standard on-off lighting mechanism in the base case, the BIPV proves to have a higher total annual energy saving potential for most orientations, upto $33.5 \%$ while dynamic EC was best suited for the North orientation resulting in $7.4 \%$ reduction in the total annual energy consumption.
\end{abstract}

Keywords: Renewable Energy; BIPV; EC Glazing; Office Building; UAE; Computer Simulation

\section{Introduction}

During the rapid construction boom, before the global economic crisis, there were approximately one third of the world's construction cranes operating in the UAE. There has been a tremendous shift in building construction over the past 40 years. In general the sunlight architecture that once tried to avoid solar gain by using small windows and appropriate shading devices has become obsolete. Other traditional elements such as the Badgir which functioned to naturally ventilate the buildings are now merely a decorative feature used for cultural association. The vernacular architecture of this region, based on high thermal mass and natural ventilation, has been outdated with modern skyscrapers. In 2010, Dubai claimed the title for the world's tallest building with the opening of the Burj Khalifa, a massive 828 meter tall structure. The estimated 400 office towers in the dense Business Bay District follow the concept of daylight architecture and try to maximize penetration of natural light. However, these large glazed areas lead to inefficient energy consumption and high operating costs. These buildings function mainly due to heavy reliance on mechanical support particularly use of air-conditioning that runs on low cost electricity from fossil fuel [1].

However, UAE is also one of the most ambitious amongst the several oil-rich Gulf countries that have made efforts to find alternative energy sources to meet its growing need for electricity. After all, in order to maintain a life of luxury with indoor ski slopes, chilled swimming pools, and huge air-conditioned shopping malls, the dependency on oil primarily might not be such wise option. Looking at the country's past, the use of passive techniques such as the Badgir, and courtyard are prevalent in its architecture. Such measures were necessary for keeping comfortable environments through inducing stack effect particularly in the hotter months. Unfortunately with the accessibility to oil and introduction of air conditioning, these elements slowly faded. Today, they are the subject of vernacular architectural study of the region and regarded as the essence of sustainability.

The research aims to compare benefits in terms of overall building energy use that can be expected from adopting two alternative façade technologies. In order to make the study more focused, office buildings are taken as the only building typology under consideration, as they are "the largest energy consumers in the buildings 
sector" [2]. An assessment will be made of the energy benefits that might arise from installing EC glazing or BIPV instead of conventional glass across the vertical façade. The energy benefit of EC glazing will be quantified in terms of its capability to reduce the total energy consumption (from electrical lighting plus building system like HVAC) on an annual basis through providing controlled day-lit environment when compared to standard glazing with blinds. In the case of the BIPV, the study will estimate energy balance through the energy consumed for lighting and HVAC, PV energy that can be generated on site, and the resulting energy equilibrium on daily, monthly, and annual basis. Thus the research will attempt to recognize and quantify the benefits of each system according to various parameters. These can include façade orientation, concerned area of façade that the system is applied on, varying weather conditions (i.e. clear sky, overcast, etc), and possibly further exploration of these parameter in different geographical location to compare with Abu Dhabi.

\section{Literature Review}

Most building's occupants favor daylight as their primary light source. Although most developers understand the higher premium value that normally comes with a space with more windows, the effects of "extensive daylighting on organizational efficiency" is not as well considered [3]. In the building sector, an increase in demand for sustainable energy and strategies for management of natural light indoors and its relationship with artificial lighting requirements has led to exploration of alternative façade designs. One of the most active areas in building design is advancements of technologies related to windows and specifically the glass. The driving forces behind such breakthroughs are issues related to interior day-lighting enhancement, maximizing occupants view and comfort, and reducing operational costs. Consequently these also have an environmental impact which makes the focus on glass worthwhile. In addition, other factors such as cultural mentality, health regulation, and occupant expectations have added to the momentum towards "healthy buildings" through use of unconventional façade designs [4].

\subsection{Building Integrated Photovoltaic (BIPV)}

Most people associate solar energy with flat-panel PV systems. They are based on crystalline silicon solar cells that convert the sun's rays directly into electricity. The two types of these cells are mono-crystalline and poly (multi)-crystalline. The easiest way to visually identify the difference between them is that the polycrystalline has a shattered glass look, while the mono-crystalline cells tend to be uniform in appearance, Figure 1. The

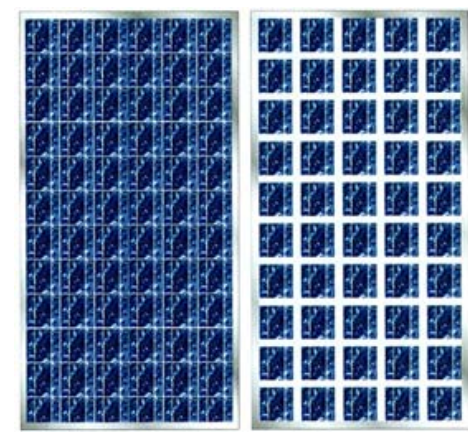

Figure 1. Opaque and semi-transparent polycrystalline PV module [5].

price and performance of polycrystalline silicon solar module is lower than that of mono-crystalline and they are the most common type of these cells. Mono-crystalline cells are cut from silicon chunks grown from a single crystal. Their applications are for more expensive types of solar panels and are more efficient in converting the sun's rays to electricity. A polycrystalline cell is cut from multifaceted silicon crystal. More surface area is required due to inherent flaws and these panels are less efficient in converting the sun's rays. However, polycrystalline technology has closed up the performance gap in recent years with nominal efficiency of $15 \%$ compared to $17 \%$ in mono.

PV can be used in a variety of ways on a building surface, combining energy production with other functions of the building envelope such as façade and roof integration, sun shades, and balcony rails. A type of PV application is Building integrated photovoltaic (BIPV) which is an ideal solution to reduce peak grid-supplied power dependency, and provide new façade design. However, the energy efficiency of BIPV, for example placed as spandrel glass panel, is 50\% less compared to "optimally placed PV module” such as roof-mounted angled arrays used primarily for power generation [4].

According to the International Energy Agency (IEA), in order to assess potential of BIPV, an analysis of building skin suitability is required [6]. This can be defined as two categories: architectural suitability taking into account limitations due to constructions, shading, and available surfaces, as well as solar suitability which considers amount of incident solar flux on the surface based on orientation, inclination and location and performance of characteristic of the BIPV system. One of the advantages of BIPV as an alternative façade is that is produces electricity while allowing daylight to penetrate the internal spaces. This will further reduce building energy consumption by providing diffused light that will ultimately reduce need for artificial lighting and hence air-conditioning. It offers a variety of possibilities for building integration given that the panels have the best orientation toward the sun, usually south facing in the 
Northern hemisphere. Besides good orientation, which ensures optimum solar irradiance, another critical design issues is adequate ventilation. Without sufficient air gaps on the back of the modules, overheating of the modules causes reductions in outputs. Another important concern is maintaining a clear obstruction from surrounding building parts or trees that may cause shading. This is crucial for a continuous optimum performance. Any part that is shaded will reduce the overall module efficiency. Chaar et al. [7] discusses the effects of wind-blown sand and dust on PV arrays in the UAE. Despite the good sunshine conditions in UAE, Chaar highlights the other climatic conditions such as high temperatures and occasional strong winds that cause perpetual sandstorm. Because these factors tend to produce different results than performing laboratory testing, hence the application of PV arrays must be studied for its feasibility in such extreme environment.

\subsection{Electrochromic Glazing (EG)}

A new type of dynamic glazing, also called smart window, can change transparency in response to external changes. There are three technologies that work on this principle: liquid crystals, suspended-particle devices, and chromic materials. There are four categories of chromic devices: electrochromic (EC) which responds to electrical voltage, thermochromic that responds to heat, photochromic which responds to light [8] and gasochromic that reacts to oxidizing gases like H2 [9]. This paper will focus on electrochromic type which can be used to control heat and light in windows. EC glazing is part of a new group of technologies called switchable glazing or smart window. Its energy reduction potential can be achieved through control of solar heat, daylight and glare. There are various types of EC windows. One of the most common one is metal oxide EC such as tungsten. Tungsten oxide (WO3) is well known for it good EC properties and stability. Figure 2 shows the configuration which is a five-layer WO3 coating sandwiched between two glass panes.

This technology works by passing a low-voltage electric current across a microscopically-thin coating on the glass surface. This activates the EC layer that causes its color to change from clear to dark, hence changing the window's transparency. A product by one of the leading manufactures has a dynamic range of 3.5\% - 64\% [10]. This means that on the low (dark) end, it blocks all but $3.5 \%$ of incoming visible light and most of the heat, while on high (clear) end, it blocks only 36\% incoming lights, and allows in more solar heat. One of the advantages EC glazing is that it only requires electricity to change its opacity but not to maintain a particular shade. It has a good durability and can be cycled from clear to tinted over 100,000 times without any functional loss [11]. Another advantage is that unlike Low-E coatings that are only appropriate for one type of climate, this type of smart glass can regulated depending on the specific needs. Further, in contrast to blinds, they are capable of partially blocking light while giving a clear view of outside. A performance characteristic of ECG that might limit its use is its switching speed. Because this transition takes three to five minutes, the amount of light entering the room is limited by the delay in the response of the window. Due to this time needed to tint the glass, the "standard use is to control the system for two states: clear and fully tinted" [11]. Another disadvantage is the inconsistency in the tint change. This is known as the "iris effect" where color change begins at outer edges of the window and slowly towards the center [12].
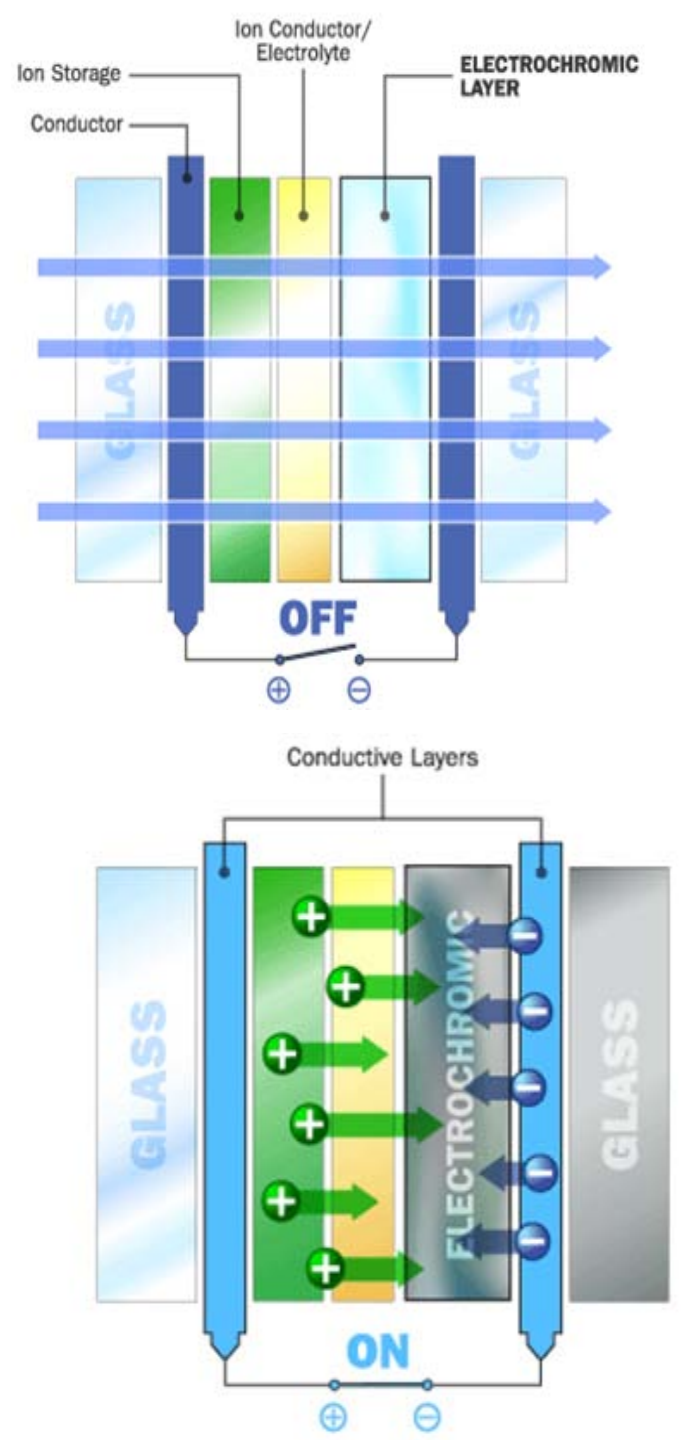

Figure. 2 Layers of EC glazing and the working mechanism [13]. 


\section{Methodology}

The advanced computer software program Integrated Environmental Solutions - Virtual Environment (IES-VE) was used to run the various configurations. There are several important criteria in choosing the correct software tool for this study. The following are a pre-requisite that were deemed necessary by the author in a computer program to be capable of handling this study:

-Ability to model BIPV and mimic characteristic of EC glazing

-Reliable with validation certificates

-Used by other scholars in similar research

-Comprehensive database of various building construction materials

A study by Crawley et al. [14] compared the twenty simulation programs under a number of functions and capabilities. From the analysis, IES-VE software achieved the best score and thus was selected for this study.

\subsection{The Simulation Models}

The basic model established for this simulation study represents the common construction practice in the Emirate of Abu Dhabi. The space configuration as well as the type of materials incorporated into the model is frequently found in UAE building construction. The space modelled, shown in Figure 3, has a rectangular shape of $4 \mathrm{~m}$ (width), 6m (depth), and 3m (height). There is a plenum of $1 \mathrm{~m}$ height, which brings the total floor to floor height to $4 \mathrm{~m}$. The façade is a typical curtain wall construction, with a flush window size of $4 \mathrm{~m}$ width and $3 \mathrm{~m}$ height consisting of double-glazing unit. Hence, the façade ratio of glazing to solid (or window to wall ratio WWR) will be $75 \%$ vision glass and $25 \%$ solid. The façade is also modelled with interior roller blinds. The blinds were either fully up or fully lowered over the whole window.

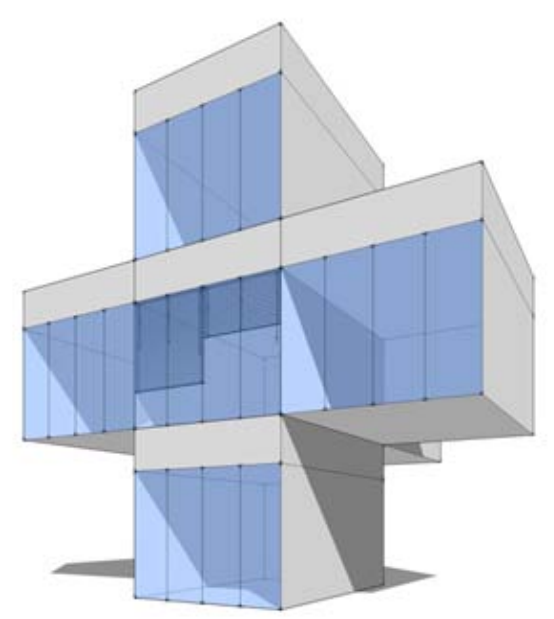

Figure. 3 Axonometric of the simulation model.
A base-case situation will provide the common ground from which the energy benefits of both the EC glazing and BIPV can be established. In this situation, there will be lights with on and off switch that can provide normal working conditions up to 500 lux. These lights will only be linked to an automated sensor that will switch them off beyond illuminance levels of 500lux. This model uses roller blinds for daylight control. The operation of blinds would be triggered by automatic sensors determining daylight levels going above 2000lux, thus giving protection from glare. And whenever illuminance levels are below this value, the blinds would be retracted. Although this automated control does not match accurate human behavior, it will primarily be used as a comparison benchmark.

\subsection{Electrochromic Glazing Control Strategy}

The software does not have the capability of dynamically changing the glazing properties, based on fluctuations in illuminance levels. Instead the performance of EC glazing, as it switches from bleached (high transmission state) to colored (darkened to a highly tinted state), will be examined by manually testing various tinting conditions on an hourly basis. Based on available technology, it is assumed that the range of visible transmittance in the model could vary between $3.5 \%$ and $62 \%$. For this model, the standard glazing will be replaced by EC glazing. Previous researches have shown that the best energy performance is achieved by daylight control switching of EC, mostly because of the "large electric lightning load reduction from day-lighting” [15]. The lighting mechanism will be similar to the base-case, where dimming control will be used to maintain a constant lighting condition of 500lux levels from natural light with artificial lights acting as supplementary. In this scenario, the EC glazing will be considered in full tint mode during non- working hours and weekends. The objective of this model is to evaluate the contribution of dynamic glazing and dimming control in the overall energy consumption.

\subsection{BIPV Model Strategy}

Part of this study is to explore some of these different Monocrystalline PV technologies to compare their benefits against each other. An annual simulation will identify the best type based on total light energy, total electricity, total displaced electricity, and the total energy balance. The models use BIPV that are integrated in various ways within the facade of a room with similar configuration as the base office module. The software can quantify the total annual electrical output from the BIPV based on the measured area on the facade. The outcome of this exercise will form a baseline of optimum BIPV model for assessment against the EC glazing and the base case 
model. Table 1 shows the matrix of different scenarios that will be tested for this reason.

\section{Results and Discussion}

The summary of the overall results of the BIPV tests shown in Table 2 indicate that case no. 5 has the lowest total energy. Another important aspects is proper lighting conditions and glare protection. Glare is commonly caused by either the excessive luminance values in the field of view and or too high luminance contrasts. Windows can have a high luminance compared with other luminances in a room. This gives a strong contrast from inside to outside, potentially causing glare.

Based on the results in Table 2 BIPV case 5 is used

Table 1. Test matrix of BIPV simulation cases.

\begin{tabular}{cccc}
\hline & \multicolumn{3}{c}{ Building Model Properties } \\
\cline { 2 - 4 }$\#$ & Transparency & Façade Integration & $\begin{array}{c}\text { Available } \\
\text { area }\left(\mathrm{m}^{2}\right)\end{array}$ \\
\hline 1 & Semi & Checkered & 7.125 \\
2 & Opaque & Vorizontal Bands & 6 \\
3 & & Only replaces Spandrel & 6 \\
4 & & Checkered with Spandrel & 11.125 \\
\hline
\end{tabular}

Table 2. Energy consumption and production summary of the different BIPV configurations studied.

\begin{tabular}{|c|c|c|c|c|c|c|}
\hline & \multicolumn{6}{|c|}{ Case number } \\
\hline & $\begin{array}{l}\text { Base } \\
\text { model }\end{array}$ & 1 & 2 & 3 & 4 & 5 \\
\hline $\begin{array}{l}\text { Direct Lighting } \\
\text { Energy (MWh) }\end{array}$ & 0.363 & 0.567 & 0.463 & 0.444 & 0.194 & 0.567 \\
\hline $\begin{array}{l}\text { Cooling Load } \\
\text { Energy (MWh }\end{array}$ & 4.595 & 3.074 & 2.912 & 2.905 & 3.133 & 3.074 \\
\hline $\begin{array}{l}\text { Total Electricity } \\
\text { Consumption } \\
\text { (MWh) }\end{array}$ & 4.96 & 3.641 & 3.375 & 3.348 & 3.327 & 3.641 \\
\hline $\begin{array}{c}\text { Total Energy } \\
\text { Produce by BIPV } \\
\text { (MWh) }\end{array}$ & NA & 0.711 & 0.598 & 0.598 & 0.399 & 1.109 \\
\hline $\begin{array}{l}\text { Net Total Energy } \\
\text { Consumption } \\
\text { (MWh) }\end{array}$ & 4.96 & 2.931 & 2.776 & 2.750 & 2.928 & 2.532 \\
\hline $\begin{array}{l}\text { Reduction in Net } \\
\text { Total Energy } \\
\text { Consumption }\end{array}$ & NA & $40.9 \%$ & $44.0 \%$ & $44.5 \%$ & $40.9 \%$ & $48.9 \%$ \\
\hline
\end{tabular}

for the second part of this research, i.e. comparison with the use of EC glazing. Seven EC configurations were tested, the difference being the level of tenting if each case. The tenting values used were: $15 \%, 30 \%, 45 \%$, $60 \%, 75 \%, 90 \%$ and dynamic tenting (i.e. variable tenting based on the level of natural light available throughout the day). The modeling was done for four design days (March 21, June 21, September 21 and December 23) representing the four seasons of the year. The simulations were also conducted for four different orientations (North, East, South and West). The use of EC is expected to reduce the energy consumption by reducing the solar gain in the space. Figures $\mathbf{4}$ and $\mathbf{5}$ show the cumulative annual percentage change in energy consumption for BIPV case 5 as well as all seven EC configurations for the South and

North orientations, respectively. EC was able to reduce the annual energy consumption by as much as $11.2 \%$ for the case of South facing dynamic EC configuration, Figure 4. It is interesting to note that the use of EC can also

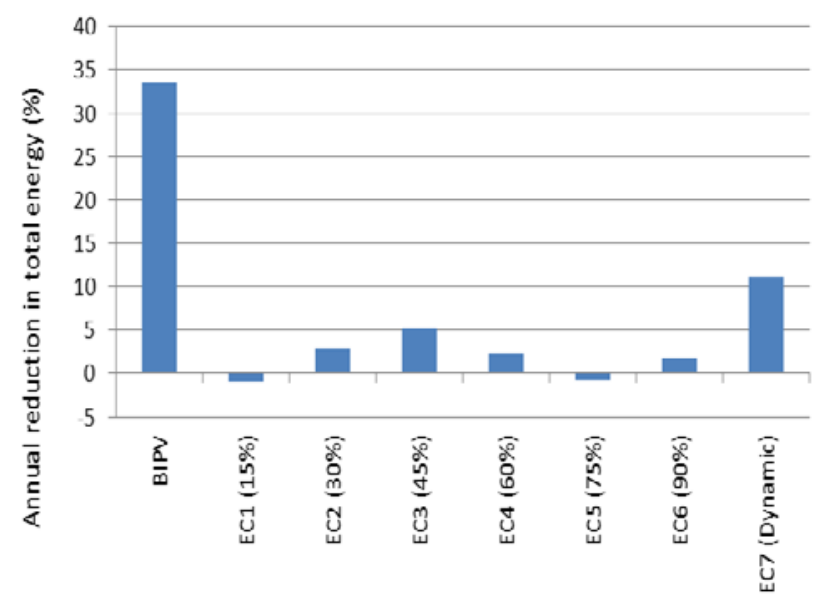

Figure 4. Change in total annual energy consumption, South facing orientation.

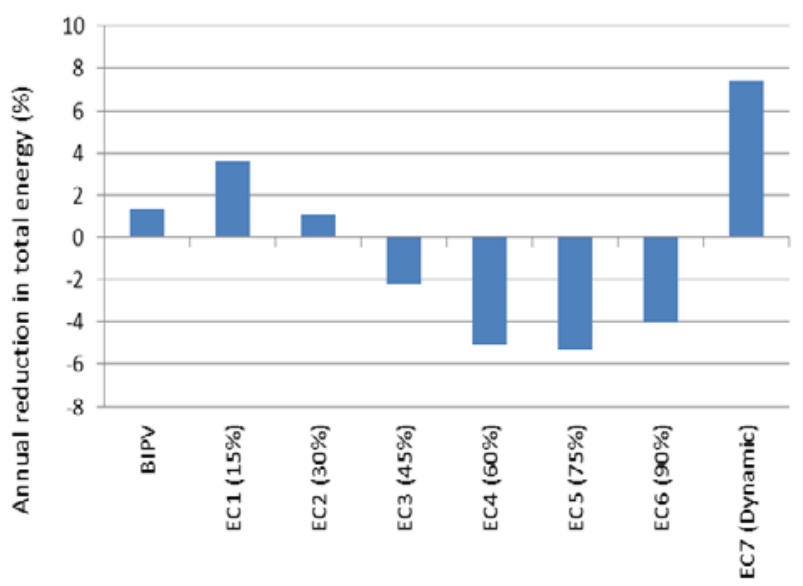

Figure 5. Change in total annual energy consumption, North facing orientation. 
result in increased annual energy consumption, as much as $5.4 \%$ for the North facing EC with $75 \%$ tenting, Figure 5. This is due to the need for more artificial light when low natural light reaches the interior of the space due to the high tenting of the EC The other important result seen is that BIPV results in lower energy consumption for the South orientation, energy reduced by $33.5 \%$ compared to $11.2 \%$ for the dynamic EC as seen in Figure 4. As for the North orientation dynamic EC resulted in $7.4 \%$ reduction in energy while the BIPV reduced the energy by $1.4 \%$ as seen in Figure 5 . The main reason for that is that BIPV does not function well in the North orientation due to the lack of direct sunlight. The BIPV results for the East and West orientations fall in between results of the South and North orientations with an annual energy savings of $16.7 \%$. On the other hand, dynamic EC performed poorly in the East and West orientations with an annual energy reduction of only $1.4 \%$. These results show that BIPV is best suited for orientations in which there is direct sunlight (East, South and West) while dynamic EC is best suited for the North direction.

\section{Conclusions}

This research studied the application of BIPV and EC glazing as an alternative façade to conventional glazing and blinds within the climate of Abu Dhabi using the IES-VE energy modelling software. Three different simulation models were created to test all the configurations with various changing parameters. The study showed that the BIPV model resulted in the most annual energy saving amongst for three of the four orientations (East, South and West) upto 33.5\% while dynamic EC resulted in the most annual energy for the North, upto 7.4\%. Improper application of EC could result in increased annul energy consumption, by as much as $5.4 \%$ for the case of South orientation with $75 \%$ tenting. The results can be used to significantly reduce the annual energy consumption in an office building located in Abu Dhabi-UAE.

\section{REFERENCES}

[1] H. Askar, S.D. Prober and W.J. Batty, "Windows for buildings in hot arid countries,” Applied Energy, Vol. 70, No. 1, 2001, pp. 77-101

[2] P. McCarthy and P. Mihlmester, "HVAC audits,” Journal of Property Management, Vol. 62, No. 1, 1997, pp. 60-63

[3] P. Boyce, "Editorial," Lighting Research and Technology, Vol. 37, No. 1, 2005, pp. 1-2

[4] C.C. Sullivan and B. Horwitz-Bennett, Barbara, "Novel Glass Technologies," Building Design \& Construction, No. 6, 2008, pp. 61-68

[5] RHC (Shenzhen RUIHUA Construction Co. Ltd.) 2008 http://www.rhc.com.cn

[6] G. Hope, “The sun shines on BIPV,” 2009 http://www.constructionweekonline.com/article-7330-thesun-shines-on-bipv/

[7] L. Chaar, A. Jamaleddine, F. Ajmal and H. Khan, "Effect of Wind Blown Sand and Dust on PV Arrays Especially in UAE”, Power Systems Conference (PSC), South Carolina USA, March 2008

[8] C.G. Granqvist, P.C. Lansaker, N.R. Mlyuka, G.A. Niklasson and E. Avendano, "Progress in chromogenics: new results for electrochromic and thermochromic materials and devices," Solar Energy Materials and Solar Cells, Vol. 93, No. 12, 2009, pp. 2032-2039

[9] V. Wittwer, M. Datz, I. Ell, A Georg, W. Graf and G. Walze,'Gasochromic windows," Solar Energy Materials and Solar Cells, Vol. 84, No. 1-4, 2004, pp. 305-314

[10] SaeGlass 2010, www.sage-ex.com

[11] S. Rudolph, J. Dieckmann and J. Brodrick, "Technologies for Smart Windows,” ASHRAE Journal, Vol. 51, No. 7, 2009, pp. 104-106

[12] G.M. Sottile, "Smart Glass Appeals to Green Community,” Windows and Door Magazine, 2008.

[13] K. Bonsor, 2010, "How Smart Windows Work," www.tlc. howstuffworks.com/home/smart-window.htm

[14] D. Crawley, C. Pedersen, L. Lawrie and F. Winkelmann, "EnergyPlus: Energy simulation program," ASHRAE Journal, Vol. 42, No. 4, 2000, pp. 49

[15] C.C. Sullivan, M. Rubin and S. Selkowitz, 'Energy Performance Analysis of Prototype Electrochromic Windows,” ASHRAE Transactions, Vol. 103, No. 1, 1997 pp. 149. 